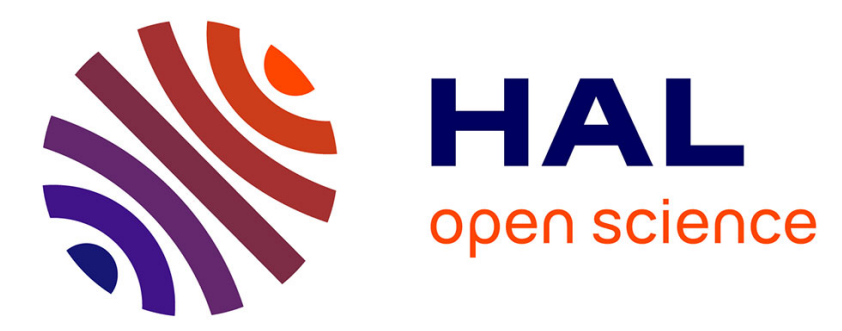

\title{
Individuals Among the Pots: How Do Traditional Ceramic Shapes Vary Between Potters?
}

Enora Gandon, Thelma Coyle, Reinoud Jan Bootsma, Valentine Roux, John Endler

\section{- To cite this version:}

Enora Gandon, Thelma Coyle, Reinoud Jan Bootsma, Valentine Roux, John Endler. Individuals Among the Pots: How Do Traditional Ceramic Shapes Vary Between Potters?. Ecological Psychology, 2018, 30 (4), pp.299 - 313. 10.1080/10407413.2018.1438200 . hal-01898499

\section{HAL Id: hal-01898499 \\ https://hal-amu.archives-ouvertes.fr/hal-01898499}

Submitted on 18 Oct 2018

HAL is a multi-disciplinary open access archive for the deposit and dissemination of scientific research documents, whether they are published or not. The documents may come from teaching and research institutions in France or abroad, or from public or private research centers.
L'archive ouverte pluridisciplinaire HAL, est destinée au dépôt et à la diffusion de documents scientifiques de niveau recherche, publiés ou non, émanant des établissements d'enseignement et de recherche français ou étrangers, des laboratoires publics ou privés. 
archives-ouvertes

\title{
Individuals Among the Pots: How Do Traditional Ceramic Shapes Vary Between Potters?
}

\author{
Enora Gandon, Thelma Coyle, Reinoud Bootsma, Valentine Roux, John
} Endler

\section{- To cite this version:}

Enora Gandon, Thelma Coyle, Reinoud Bootsma, Valentine Roux, John Endler. Individuals Among the Pots: How Do Traditional Ceramic Shapes Vary Between Potters?. Ecological Psychology, Taylor

Francis (Routledge), 2018, 30 (4), pp.299 - 313. <10.1080/10407413.2018.1438200>. <hal-01898499>

\section{HAL Id: hal-01898499 \\ https://hal-amu.archives-ouvertes.fr/hal-01898499}

Submitted on 18 Oct 2018

HAL is a multi-disciplinary open access archive for the deposit and dissemination of scientific research documents, whether they are published or not. The documents may come from teaching and research institutions in France or abroad, or from public or private research centers.
L'archive ouverte pluridisciplinaire HAL, est destinée au dépôt et à la diffusion de documents scientifiques de niveau recherche, publiés ou non, émanant des établissements d'enseignement et de recherche français ou étrangers, des laboratoires publics ou privés. 


\title{
Individuals Among the Pots: How Do Traditional Ceramic Shapes Vary Between Potters?
}

\author{
Enora Gandon ${ }^{\mathrm{a}}$, Thelma Coyle ${ }^{\mathrm{b}}$, Reinoud J. Bootsma ${ }^{\mathrm{b}}{ }^{\mathrm{b}}$, Valentine Roux ${ }^{\mathrm{c}}$, \\ and John Endler (iD) ${ }^{d}$ \\ ${ }^{\mathrm{a}}$ Institute of Archaeology, UCL; ${ }^{\mathrm{b}}$ Aix-Marseille Université, CNRS, ISM, Marseille; ${ }^{\mathrm{C} C N R S}$, University Paris-Nanterre; \\ ${ }^{\mathrm{d} C e n t e r}$ for Integrative Ecology, School of Life \& Environmental Sciences, Deakin University
}

\begin{abstract}
At the crossroad of archeology and experimental psychology, we addressed the issue of interindividual variability in traditional ceramic shapes. The goal was to explore whether such variability could imply potter signatures. We set up a field experiment with 5 expert Nepalese potters, asking them to produce 3 shapes (replicated 5 times). The $2 \mathrm{D}$ profiles of the experimental productions were analyzed with a shape analysis method borrowed from biology. In a complementary experiment focusing on shape discrimination, the participants were asked to visually identify their own productions and those of their colleagues. Results indicated that the potters produced slightly but significantly different shapes. We assume that during apprenticeship individuals developed their own motor skills, which reflect upon the finished products. Interpreting shape variability in terms of individuals could provide supplementary information on the social organization of the production, either for modern or ancient periods. As for shape discrimination, our preliminary results indicated that a few potters visually distinguished individual signatures. Those craftsmen could play a key role in the selection and evolution of the traditional ceramic shapes.
\end{abstract}

Human inheritance is not only genetic but also cultural (Boyd \& Richerson, 1985; Cavalli-Sforza \& Feldman, 1981; Richerson \& Boyd, 2005). Both biological and cultural attributes evolve through the successive mechanisms of (a) production of variations, (b) transmission of variations, and (c) differential selection of variations (Cavalli-Sforza \& Feldman, 1981; Endler, 1986; Lewontin, 1971). Because they subsist across generations, human artifacts are cultural attributes that are particularly suitable for the study of cultural evolution. In this respect, knapped stones and ceramics are generally considered of prime interest. From a behavioral point of view, individuals learn to produce cultural artifacts channeled by their social surrounding and they transmit these cultural artifacts to their peers and to the younger generations. In this light, one may ask to what extent cultural artifacts are influenced by an individual's own style. Adopting an experimental approach, 
in this contribution we analyze the interindividual variations in traditional ceramic shapes produced by Nepalese craftsmen.

As a widespread, traditional, and artisanal skill, wheel-throwing provides an excellent model for analyzing the cultural transmission and evolution of motor skills and their ensuing artifacts (Gandon, 2014; Gandon, Bootsma, Endler, \& Grosman, 2013; Gandon, Coyle, \& Bootsma, 2014; Gandon, Roux, \& Coyle, 2014). Starting with a formless lump of clay, the goal of wheel-throwing is to produce a pot-of a shape and size chosen in advance-using a wheel rotating in the horizontal plane at speeds varying between 50 and 150 rotations/min (Gandon, Pous, Coyle, Buloup, \& Bootsma, 2011; Pierret, 2001; Rye, 1977). Ceramics are primarily defined by their shapes, which correspond to specific uses (such as storage, cooking, or rituals). Our ethnographic observations in workshops located in different cultural settings (France, Morocco, Turkey, India, Nepal, Thailand, and Spain) indicated that expert craftsmen usually reproduce the traditional ceramic shapes by relying on their practical experience (i.e., without requiring any visual model). One could say that these shapes are standard shapes (in their cultural area) in the sense that they are called by specific names and well recognized by craftsmen and customers. Ethnoarcheological studies have long documented that traditional ceramic shapes characterize cultural groups, although borrowings are sometimes noted between distinct groups (Gelbert, 2002; Gosselain, 1992, 2000; Hodder, 1979). In archeology, ceramic shapes are classified according to morphometric attributes that are then put in relation with functions, places, or periods in order to construct functional or chronocultural "types" (Gardin, 1980; Karasik \& Smilansky, 2011; Orton, 1993; Read, 2009; Whallon, 1972). The variability of these types is used by archeologists to construct the history of ancient societies. In the present context, we call the ceramic shapes "traditional" in the sense that they are the outcomes of motor skills transmitted through lineages of specialized craftsmen (Cochrane, 2008, 2013; Eerken \& Lipo, 2007).

Although they result from transmitted gestures, traditional ceramic shapes tend to change over time if no operations of stabilizing selection occur (Cochrane, Rieth, \& Dickinson, 2013; Orton, 1993). Change indicates the existence of sources of variation in the production of ceramic shapes and/or in the cultural transmission of these shapes. Certain sources of variation (such as borrowing through interactions between populations, or innovations due to external factors like evolution of the market demand) come from the socioeconomic context (Kramer, 1985; Winslow, 2009). They differ from the sources of variation inherent in the practice itself, that is, occurring at the behavioral level where individuals play a role (Schiffer, 1976; Schiffer \& Skibo, 1997).

The first behavioral source of variation supposedly operates during apprenticeship, through the cultural transmission of motor skills. For learning of wheel-throwing, model observation occurs when tutors (i.e., expert potters) encourage their apprentices to observe the gestures used (i.e., adoption and sequence of specific hand positions on the lump of clay) so that they can reproduce them. In the framework of ecological psychology, motor learning of cultural skills is not understood as resulting from strictly reproducing the gestures of a model (i.e., tutor) but rather as a behavior elicited by the observation of a model (Bril, 2002a, 2015; Newell, 1991; Parry, Dietrich, \& Bril, 2015). As Bril argues, the role of a model is to orient the learner toward the discovery of any motor skill effective for the task (Bril, 2015). Following this perspective, we assume that the novice adapts the motor skill shown by the tutor. Apprentices are therefore likely to develop idiosyncratic motor skills leading to interindividual variations of the traditional shapes. In favor of this hypothesis, a study 
conducted on three groups of potters (French, Multani-Kumar Indian, and Prajapati Indian) revealed that expert potters belonging to the same cultural group shared a considerable part of their hand position repertoires but also developed some individual-specific hand positions (Gandon, 2014).

The second behavioral source of variation in craft production is (so-called) copying error, which has been empirically highlighted (Eerkens \& Lipo, 2005; Gandon, Roux, \& Coyle, 2014; Hamilton \& Buchanan, 2009; Kempe, Lycett, \& Mesoudi, 2012; Schillinger, Mesoudi, \& Lycett, 2014; Steele, Glatz, \& Kandler, 2010). Copying error has been defined as "a small amount of error introduced into any copying event in which information is communicated about what an artifact should look like and how it should be made" (Eerkens \& Lipo, 2005, p. 321). According to Eerkens and Lipo (2005), copying errors are generated through (a) errors in perception generated by cognitive limits in evaluating metric differences between two objects and (b) errors due to imprecision in manual dexterity. Intrinsic to any handicraft, copying error occurs throughout the potter's career and gives rise to intraindividual variations in produced artifacts. In other words, perceptual/cognitive and dexterity limits would explain why potters, whatever their skill level, cannot produce perfectly standardized assemblages of given types. The degree of ceramics standardization has been shown to increase with the frequency at which the ceramics are made, with highly standardized ceramics being characterized by a coefficient of variation of around $3 \%$ and even less in the case of mass production (Gandon, Casanova, et al., 2011; Gandon, Roux, \& Coyle, 2014; Roux, 2003).

Thus, although the traditional ceramic shapes are identified as standard shapes by craftsmen and customers, in fact these shapes vary at the intraindividual level due to copying error; we assume that they also vary at the interindividual level due to the learning process. Some of these variations may then be transmitted, and different selective forces can operate on them causing evolution of the traditional shapes. It is likely that the interindividual variations (occurring during learning) are particularly important for the cultural evolutionary process. Indeed, we hypothesize that individuals develop their own manner of producing the traditional ceramic shapes, developing-consciously or nottheir own style. Yet, empirical assessment of such interindividual variations in ceramic shapes of the same type is still in its early stages. Roux and Karasik (in press) recently studied a type of wheel-thrown water jar produced in North India by contemporary potters and did indeed report small but identifiable shape differences among potters. In the present study, we expect to confirm these first results. We decided to follow the ethnoarcheological approach of Roux and Karasik because experimenting with contemporary potters is the only way to provide direct evidence regarding the existence of individual features on ceramics. For present purposes we chose to work in Nepal, a country where the pottery handicraft is still organized in a traditional way. We analyzed the $2 \mathrm{D}$ profiles of three different traditional ceramic shapes produced, in five replicates, by each of five expert potters working in their familiar conditions of practice. The shape analysis method used in this study was borrowed from biology (McLellan \& Endler, 1998). This method-detailed later-provided an accurate quantification of variation in shape within and among potters, allowing statistical tests and direct estimates of variation. Going a step further, in a complementary experiment we examined the ability of potters to visually identify the individual styles in the experimental assemblage. If individual styles indeed exist, their identification by potters could be determinant in terms of cultural selection. 


\section{Method}

The field experiment took place in a traditional pottery workshop in Bhaktapur (Nepal, Kathmandu district). As in India, the pottery handicraft in Nepal is learned within endogamous castes that produce standardized traditional objects in mass production (Kramer, 1997; Roux \& Corbetta, 1989; Saraswati \& Behura, 1964). In the Newar community of Bhaktapur the electrical wheel has been adopted since 2009. Five expert potters gave their written consent to participate in the experiment: LAX, SAN, RAM, SHI, and DIN. The participants all originated from Bhaktapur and belong to the Newar community (Prajapati Hindu caste). They work either in the same pottery workshop (LAX and SAN are father and son) or in neighboring workshops (same street; DIN, who is SAN's brother, and RAM and SHI, who are SAN's uncles). They use the same clay, share the same drying area (which is the central square), and fire their pots in two shared kilns. Moreover, they manufacture the same traditional shapes responding to the same market demand. The participants (all right-handed men) were all over 25 years old ( $M \pm S D: 38.0 \pm 8.7$ years) and had a minimum of 10 years of wheel-throwing experience ( $26.0 \pm 8.9$ years). These 5 potters produce traditional ceramic shapes comparable to the ones produced by North Indian potters studied by Gandon, Coyle, and Bootsma (2014). Nevertheless, as can be seen from Figure 1, their geometrical analysis demonstrated that they were clearly different. In this regard, their production thus signals a distinct cultural group.

In the main experiment, the 5 potters were asked to produce three different shapes. These three shapes are frequently made and referred to in the local language as Anchora (vessel

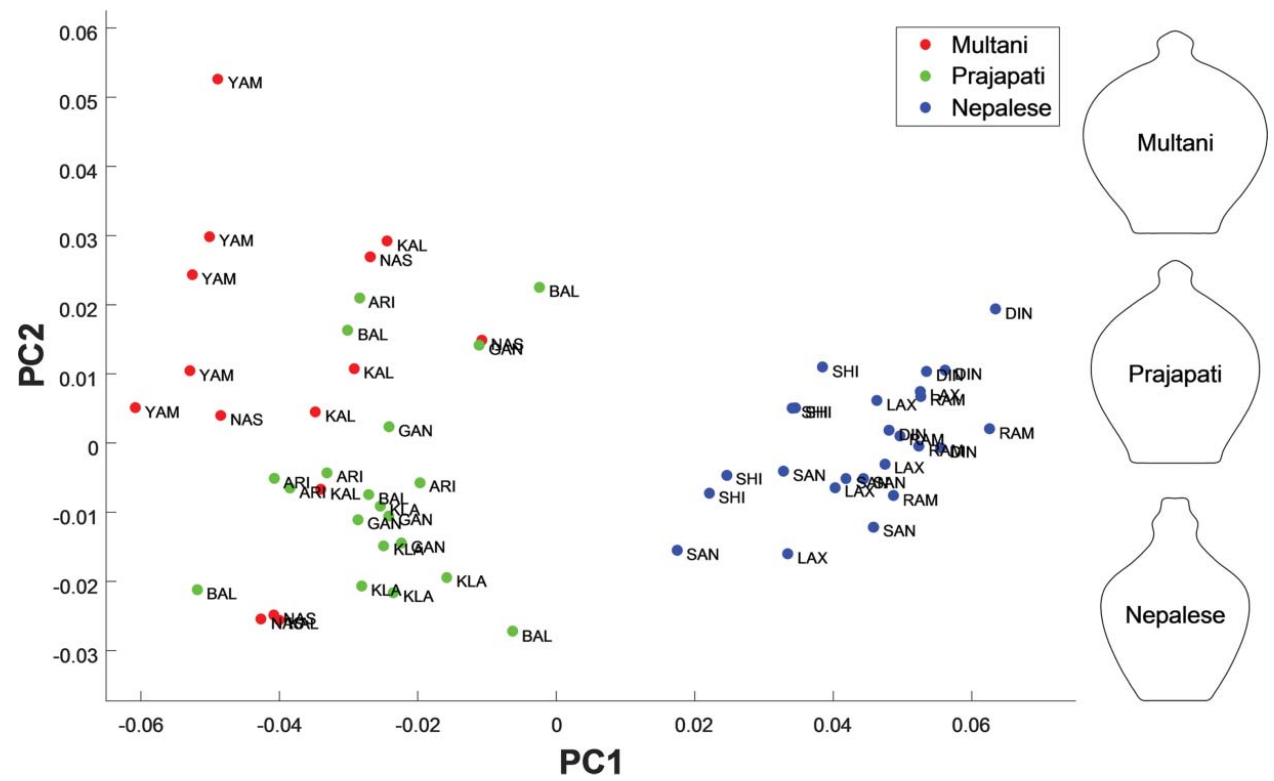

Figure 1. Geometrical distribution of the Money-Bank vessels thrown by Indian (Multani-Kumar: green; Prajapati: red) and Nepalese (blue) potters. The points in the PCA (Principal Component Analysis) space show the variations among potters, for the three groups, and are based upon elliptical Fourier coefficients derived for every pot shape. The pot outlines (to the right of the graph) are reconstructions of the shapes resulting from the mean coefficients of each group's production. 
containing water used in rituals), Money-Bank (piggy bank), and Ashtray (ashtray; Figure 2). Each of the three shapes was produced in five specimens; each potter therefore produced a total of 15 pots. In order to respect the usual conditions of practice, potters relied on their practical experience of the required shape and no visual model was presented. All potters used the same wheel and clay. No additional tools were used except a basin of water to wet the clay. No limit of time was fixed and each potter threw all 15 pots in a single session. The experimenter was present during the experimental task to monitor progress and ensure procedural consistency.

All finished pots were marked on the bottom with a number representing the specific potter and the pot number in the series; then they were put to dry for 2 days. After the drying process, we used a Canon PowerShot-SX270 camera to photograph all pots (together with a calibration object) under standardized conditions. From the pot photos we extracted the (x, y) coordinates of the cross-sectional right profiles using Gimp ${ }^{\circledR}$ and Matlab ${ }^{\circledR}$ software. The profile coordinates were converted from pixels to centimeters using a calibration factor obtained from the dimensions of the calibration object present in each image. Next, the profiles were resampled to generate an equal number of points (256 in total) at regular height intervals along the (vertical) y-axis and finally the coordinates were smoothed with a low pass filter (cf. Gandon et al., 2013; Gandon, Coyle, \& Bootsma, 2014). Because wheel-thrown vessels are typically axisymmetric, profiles were subsequently converted to full pot outlines by multiplying the $\mathrm{x}$ coordinates by -1 to create the corresponding left edge.

To characterize the geometry independent of the size of the pots produced, the analysis proceeded in several steps. First, the ensemble of profiles was submitted to an elliptical Fourier analysis (McLellan \& Endler, 1998). The resulting Fourier coefficients were then normalized to the first harmonic to remove differences in size and orientation according to the method proposed by Kuhl and Gardiena (1982). Finally, the normalized Fourier coefficients were submitted to a Principal Component Analysis (PCA). The first two Principal Components always captured over $75 \%$ of the variance. Therefore, the variation in geometry of each pot could be adequately represented as a point in the 2D PC1-PC2 space. A Permutation Test (Mielke \& Berry, 2007) was carried out on the PC scores for each of the three shape classes separately using the adonis function in the R package Vegan (Oksanen et al., 2016). This analysis tested for heterogeneity of shapes among the potters within shape types; if significant this test indicates the presence of individual influences on ceramic shapes. If not significant, then the test cannot detect any differences among the potters for a given shape. Finally, using the between-trial variabilities over the five specimens thrown by each

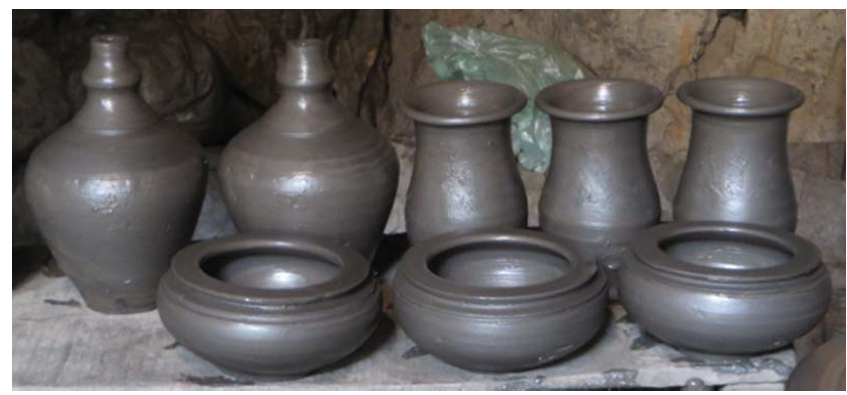

Figure 2. Traditional shape types produced in the experiment. Money-Bank (back left), Anchora (back right), and Ashtray (front). 
participant (for each of the three shapes), the standardization of production was assessed via the coefficients of variation $\left(\mathrm{CV}=100 \%{ }^{*}\right.$ standard deviation/mean) computed on the maximal diameter (centimeter precision) of the pots.

In a complementary experiment, following the drying period we asked each of the 5 participants to identify their own productions and those of their 4 colleagues within the assemblage. To this end, we selected, for each of the 5 potters and for each of the three shapes, the best four specimens (allowing elimination of pots with manufacturing defects). This was done to prevent a potter recognizing his pot because of the presence of a noticeable defect (e.g., a fingerprint in the wall, or a little rock in the clay). The pots were then organized by groups of 4 pots per shape (x3) and per potter (x5), thereby obtaining a total of 15 groups of 4 pots (Figure 3 ). Each potter was individually asked to identify the different producers of the 15 groups of pots. In other words, looking at the total 60-pot assemblage, each potter was to identify his own pots and those of his 4 colleagues. The pots were solely observed from a distance. No feedback or any other type of clue was given. In total, each potter had to provide 15 answers (five producers to be identified for each of the three different shapes), which were entered into an Excel file.

\section{Results}

Figure 4 presents the geometrical distributions in PC1-PC2 space of each of the five specimens thrown by each of the five potters for the Anchora (top panel), Money-Bank (middle panel) and Ashtray (bottom panel) shapes. As can be seen from Table 1, for each shape the Permutation Test revealed significant heterogeneity among potters, indicating that different potters produced vessels with slight but systematical morphometric variations. We therefore conclude that, although they all threw the same three traditional shapes, potters did indeed imprint individual signatures on the vessels thrown.

For the Anchora PC1 (66.0\%) and PC2 (19.0\%) explained $85.0 \%$ of the observed profile variation. Inspection of Figure 4 (top panel) indicated that differences were mostly to be found in the width and position of the indentation below the lip. The Anchora profiles of SAN were close to those of SHI. For the Money-Bank PC1 (60.1\%) and PC2 (18.7\%) explained $78.8 \%$ of the observed profile variation. The differences among potters primarily concerned the width and height of the central bulge and to a lesser extent the height of the mouth (Figure 4, middle panel). The Money-Bank profiles of SAN were clearly distinct from those of the four other potters, whereas the Money-Bank profiles of RAM were in between those of LAX and DIN. For the Ashtray PC1 (86.2\%) and PC2 (8.4\%) explained $94.6 \%$ of the observed profile variation. For the Ashtray, variation was considerably larger than for the other two shapes; the profiles differed in the steepness of the sides, the roundness below the lip, and the shape of the lip (Figure 4, bottom panel). The Ashtray profiles of LAX were close to those of DIN.

Finally, visual inspection of the dispersion of the points in Figure 4 revealed comparable degrees of intraindividual variability for all five potters. This observation was corroborated by the CV results presented in Table 2 . Bearing in mind that these CVs were uniquely based on each vessel's maximum diameter, the CV values were generally quite similar for the five potters and the three shapes (Table 2) for an overall mean of $2.9 \pm 1.6 \%$. However, as can be seen from Table 2, the shape with the highest CV varied over potters; that is, among them they differed to a certain extent in the ability to standardize each of the different shapes. 


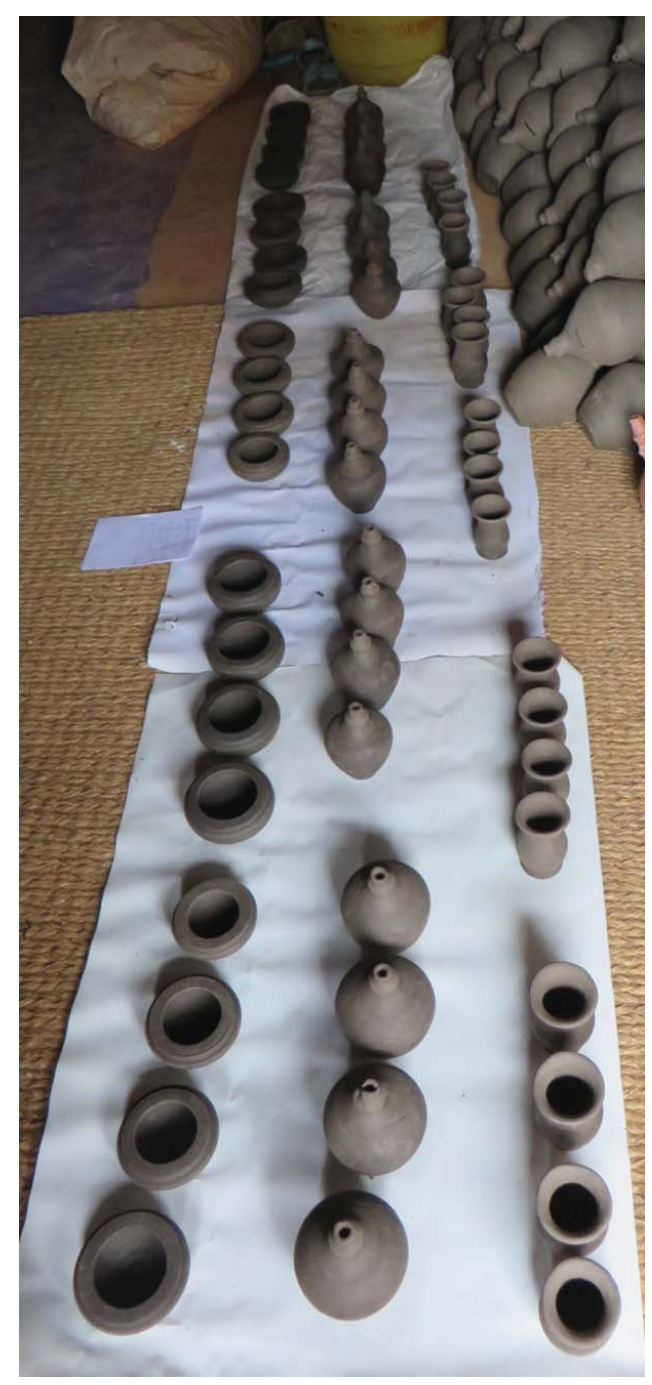

Figure 3. Experimenter view of the 15 groups of pots used in the identification task. For the three shapes (front: Ashtray, middle: Money-Bank, and back: Anchora), each potter was asked to identify the producer of the pots. The pots were simply viewed from a comfortable distance. The participants were invited to identify the producers of the pots starting from the rightmost four-pot collection and subsequently proceeding leftward. They could change their answers if deemed necessary.

Table 3 presents the answers given by each of the five potters when trying to identify their pots and those of their four colleagues. Inspection of this table shows that-for the three shapes-one potter (SAN) identified correctly all the pots (15 correct answers); another potter (SHI) identified correctly more than half of the assemblage (11 correct answers); and the three remaining potters identified correctly only one third of the assemblage $(6,5$, and 4 correct answers for RAM, LAX, and DIN, respectively). We examined whether incorrect answers (given notably by RAM, LAX, and DIN) were caused by confusion between pots with similar features. We noted, for example, in the top panel of Figure 4 that the Anchora profiles of SAN (Potter 2) were close to those of SHI (Potter 3). However, these profiles were never confused (see Table 3). By the same token, the Money-Bank pots produced by LAX 

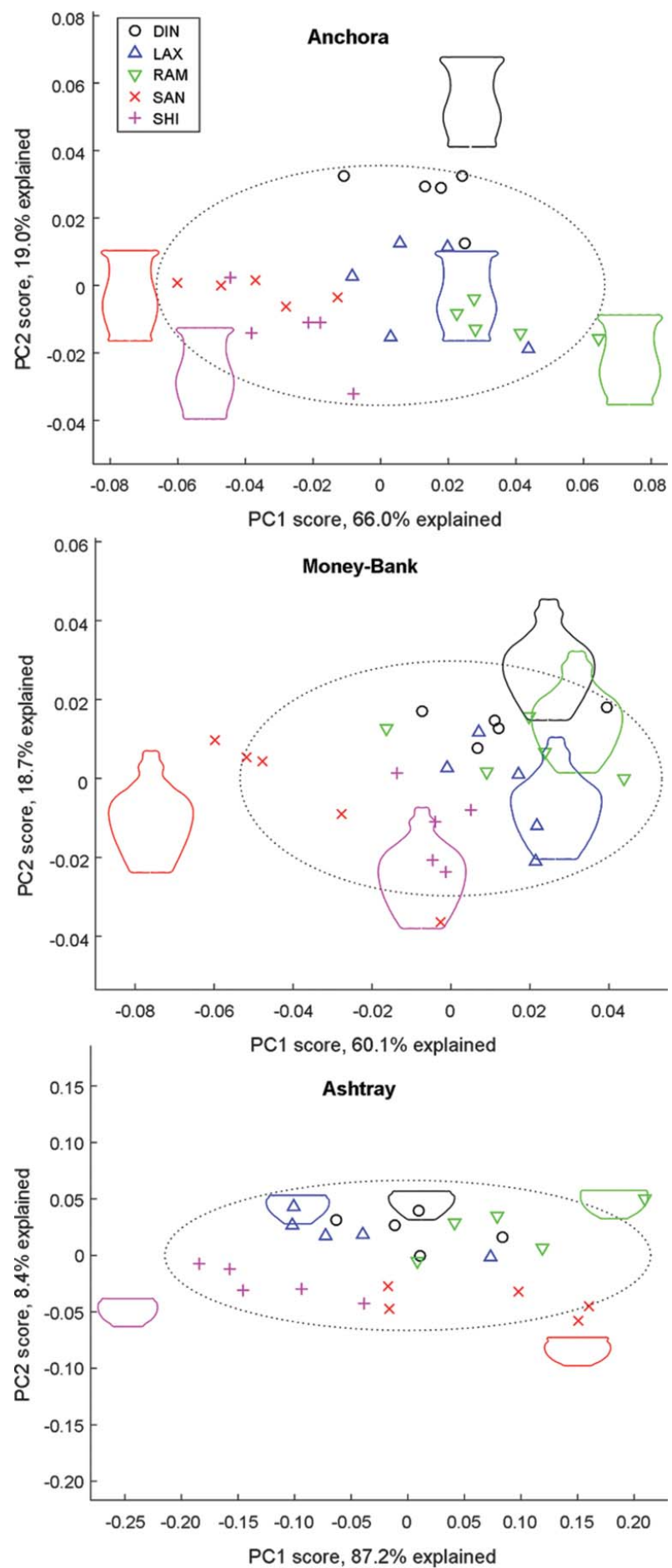

Figure 4. Geometrical distributions of thrown vessels. Anchora (top panel), Money-Bank (middle panel), and Ashtray (bottom panel). The points in the PCA (Principal Component Analysis) space show the variations within and among potters, for the three shapes separately. The pot outlines in the graph are reconstructions of the shapes resulting from the mean coefficients of each potter's production. 
Table 1. Results of the permutation test.

\begin{tabular}{llccr}
\hline Shape & Component & $d f$ & $\mathrm{R}^{2}$ & $p$ \\
\hline \multirow{2}{*}{ Anchora } & Potter & 4 & 0.687 & $<.0001$ \\
& Residuals & 20 & 0.312 & $<.001$ \\
Money-Bank & Potter & 4 & 0.521 & $<.0001$ \\
& Residuals & 20 & 0.478 & 0.616 \\
Ashtray & Potter & 4 & 0.384 & \\
& Residuals & 20 & & \\
\hline
\end{tabular}

Table 2. Mean coefficients of variation (CV) of thrown vessels.

\begin{tabular}{lcccccc}
\hline & LAX & SAN & RAM & SHI & DIN & $M$ \\
\hline Anchora & 2.8 & 3.4 & 2.0 & 1.5 & 7.0 & 3.3 \\
Money-Bank & 4.0 & 3.0 & 1.5 & 5.0 & 0.5 & 2.8 \\
Ashtray & 2.1 & 2.2 & 2.9 & 2.3 & 2.7 & 2.4 \\
$M$ & 2.9 & 2.9 & 2.2 & 2.9 & 3.4 & \\
\hline
\end{tabular}

(Potter 1), RAM (Potter 3), and DIN (Potter 5) had very similar profiles (Figure 4, middle panel), but on a total of 12 incorrect answers not even one corresponded to a confusion between RAM and DIN profiles (see Table 3). As for the Ashtray profiles, those of LAX were close to those of DIN but they were only confused one time for a total of 10 incorrect answers. Hence, it appeared that when potters were not able to recognize the producers of the pots the answers provided were not systematically related to potters' particular shape characteristics.

\section{Discussion}

The shape variability in ancient ceramic assemblages represents a rich source of material to explore the cultural evolution. Interpreting this variability requires the contribution of field experiments, allowing researchers to benefit from the expertise of both craftspeople and established analysis techniques. Based on our ethnographic observations, we assumed that, in the course of learning, potters develop their own style of practicing wheel-throwing. In doing so, they would mark the shapes of their pots with personal features that could lead

Table 3. Results of the identification task. Answers given by each of the five potters (rows) when trying to identify their pots and those of their four colleagues (columns), for the three shapes (Anchora, MoneyBank, and Ashtray). Gray: correct answers. Potter 1: LAX, Potter 2: SAN, Potter 3: RAM, Potter 4: SHI, and Potter 5: DIN. Example of reading: RAM (Potter 3) identified the Anchora of LAX (Potter 1) as being the one of SAN (Potter 2); he identified the Anchora of SAN (Potter 2) as being the one of LAX (Potter 1); he correctly identified his own Anchora (Potter 3) and those of SHI (Potter 4) and DIN (Potter 5).

\begin{tabular}{|c|c|c|c|c|c|c|c|c|c|c|c|c|c|c|c|c|}
\hline & & \multicolumn{5}{|c|}{ Potters' Anchora } & \multicolumn{5}{|c|}{ Potters' Money-Bank } & \multicolumn{5}{|c|}{ Potters' Ashtray } \\
\hline & & 1 & 2 & 3 & 4 & 5 & 1 & 2 & 3 & 4 & 5 & 1 & 2 & 3 & 4 & 5 \\
\hline \multirow[t]{5}{*}{ Potters' Answers } & 1 & 1 & 4 & 3 & 5 & 2 & 1 & 5 & 2 & 3 & 4 & 4 & 2 & 1 & 3 & 5 \\
\hline & 2 & 1 & 2 & 3 & 4 & 5 & 1 & 2 & 3 & 4 & 5 & 1 & 2 & 3 & 4 & 5 \\
\hline & 3 & 2 & 1 & 3 & 4 & 5 & 1 & 4 & 2 & 3 & 5 & 5 & 2 & 1 & 3 & 4 \\
\hline & 4 & 2 & 1 & 3 & 4 & 5 & 2 & 1 & 3 & 4 & 5 & 1 & 2 & 3 & 4 & 5 \\
\hline & 5 & 2 & 5 & 4 & 3 & 1 & 1 & 4 & 2 & 3 & 5 & 1 & 2 & 5 & 3 & 4 \\
\hline
\end{tabular}


over time to an evolution of the traditional ceramic shapes. In this contribution, we analyzed the variability of three traditional ceramic shapes produced by five Nepalese experts, potters raised and trained within the same cultural niche, in order to examine whether the experimental productions presented individual features. In a second step, we explored the ability of potters to visually identify these individual features in the experimental assemblage.

As expected, the traditional context of production and the level of expertise of the participating professional potters gave rise to highly standardized assemblages at the individual level. The values of the CVs-which we interpret as quantifications of copying error-were close to the 3\% reported in previous studies (Gandon, Casanova, et al., 2011; Gandon, Roux, \& Coyle, 2014; Roux, 2003). On the other hand, the Permutation Test on vessel shapes revealed significant differences among potters for each of the three shapes. Moreover, different potters threw different shapes with different degrees of precision. These interindividual variations in the traditional shapes thrown were clearly distinguishable in the PCA space (Figure 4). The present results thus corroborated those reported by Roux and Karasik (in press) and suggest that individual styles may also be identifiable in ancient ceramic assemblages. The patterned geometrical distribution highlighted in our study (Figure 4) could be used in archeology to provide benchmarks for attributing minor shape variations to individual signatures rather than to other factors. Identifying individual signatures in an archeological assemblage could help determine the number of artisans involved in a standardized production, which in turn would lead to a better understanding of the social context of the production (Costin \& Hagstrum, 1995; Creese, 2012; Hill, 1978; Morris, 1993; Roe, 1980; Thomas, McCall, \& Lillios, 2009).

As for the mechanisms underlying the emergence of interindividual variations in ceramic shapes, we submit that potters do indeed develop individual motor skills despite a highly constrained task (shaping vessels with the use of rotational kinetic energy) and the similarity of the cultural environment (same social group), the intended products (same three vessel shapes), the technical traditions (same clay and wheels), and the transmission context (same vertical transmission from father to son). Such a development of individual motor skills within the same cultural niche leading to minor variations in shapes is very likely related to the learning process. Learning elementary movements can be viewed as an adaptation to the constraints of the individual, the task, and the (material) environment (Bril, 2015; Newell, 1986; Reed \& Bril, 1996). This process takes place under the guidance of the social environment (notably the tutor's observation and teaching), which imprints a cultural mark on motor behavior (Bril, 2002b; Gandon, 2014). However, this cultural influence is not completely dominant. In fact, the role of the tutor is only to guide the novice. Executing a technical movement implies a mixture of common and individual strategies (Parry, Dietrich, \& Bril, 2015; Reed \& Bril, 1996; Rein, Nonaka, \& Bril, 2014). This explains that, despite belonging to the same learning network, the potters produced traditional ceramic shapes whose metric variability corresponds to individual signatures. Let us indeed recall that SAN and DIN learned from LAX and that LAX, RAM, and SHI learned from the same father.

Even if, as demonstrated in the present contribution, characteristics of individual craftsmen affect traditional ceramic shapes, the question to what extent these individual characteristics play a role in the evolution of these shapes remains open. Does the evolution of the types defined by archeologists indeed originate, at least partially, from interindividual variability? Given the high reproducibility of expert motor behaviors (Bootsma \& Van Wieringen, 1990; Gandon, 2014; Sevrez, Berton, Rao, \& Bootsma, 2009, 2012), the individual 
shapes may last long enough (at least during the life span of the craftsman and of his pots) to constitute a variant that could be transmitted and selected. In this light, we wondered whether craftsmen can detect minor differences between the shapes of the same types of objects made by different producers. If this were the case, they could select the individual variant they prefer, notably disseminating it by reproduction. In turn, this selection would then influence the shape evolution. The preliminary results obtained in the complementary experiment shed some light on this issue. The fact that one potter performed the identification task perfectly indicates that the individual signatures on ceramics assemblages are not only detectable by numerical analysis (Figure 4) but also visually. Indeed, it is highly unlikely that, for each traditional shape, SAN correctly identified the five producers of the pots simply by chance. Following E. J. Gibson's (1992) lead, we may therefore assume that he developed the perceptual ability to detect the slight shape differences present on each shape assemblage. In the present context we hypothesize a relation between shape discrimination ability and the motivation of craftsmen. Indeed, the best results were obtained by SAN, who, in discussions, demonstrated a special interest for esthetic performance in his daily work. This kind of interest could lead craftsmen like him to become more aware of the stylistic aspect of the artifacts. In his attempt to produce "beautiful shapes" (in his own words), SAN usually compared his production with those of his colleagues. In this way, we assume that he developed an acute perception of shapes and consequently of the individual signatures. Such perfectionist craftsmen could play a key role in the selection and evolution of the traditional artifacts shapes.

\section{Conclusion}

At the crossroad of archeology and experimental psychology, we addressed the issue of interindividual variability in the production of ceramic types. The goal was to explore whether such variability could imply potter signatures. Taking traditional ceramic shapes as a case study, we set up a field experiment with five expert potters from the Kathmandu district. The 2D profiles of the experimental productions (three shapes replicated five times) were analyzed with a geometrical shape analysis method borrowed from biology. In a complementary experiment focusing on shape discrimination, the participants were asked to visually identify their own productions and those of their four colleagues.

Results highlighted an expected level of individual standardization of the productions together with significant interindividual variations. Hence, although the traditional ceramic shapes are characterized by a strong cultural standardization (Gandon, Coyle, \& Bootsma, 2014), these shapes are also characterized by individual styles. Our results corroborated the original results obtained by Roux and Karasik (in press). We assume that, even though conditions of transmission and shapes produced are homogeneous within a community of practice, during apprenticeship individuals develop their own motor skills, which reflect upon the finished products. Together with those of previous studies showing that the cultural origin of potters influences the direction of the copying errors (Gandon, Roux, \& Coyle, 2014), these results can be understood within the framework of ecological psychology as showing how the constraints of the individual, the task, and the environment (both material and social) interact in the shaping of human motor behavior and in its material consequences.

In archeology, interpreting type variability in terms of individuals could provide supplementary information on the social organization of the production (domestic vs. specialized 
production, size of the workshops, distribution network) either for modern or ancient periods. Type variability could also explain the evolution of ceramic shapes when considering individual features as a source of cultural divergence. Further work is now required to understand the exact role played by the individual signatures in the evolution of ceramic shapes. In the future, we encourage field studies of cultural transmission across generations to consider the potters' gestures, the resulting shapes, and the perceptual ability of potters to discriminate the shape variations.

\section{Acknowledgments}

We are grateful to Sanjay Prajapati for welcoming and allowing us to work in his workshop and Patrick Lecouffe for providing technical assistance.

\section{ORCID}

Reinoud J. Bootsma (iD http://orcid.org/0000-0002-3719-7586

John Endler (iD http://orcid.org/0000-0002-7557-7627

\section{References}

Bootsma, R. J., \& Van Wieringen, P. C. (1990). Timing an attacking forehand drive in table tennis. Journal of Experimental Psychology: Human Perception and Performance, 16, 21-29.

Boyd, R., \& Richerson, P. J. (1985). Culture and the evolutionary process. Chicago, IL: University of Chicago Press.

Bril, B. (2002a). Apprenticeship and context. Intellectica, 2, 251-268.

Bril, B. (2002b). The apprenticeship of technical gesture: task constraints and cultural variations. In B. Bril \& V. Roux (Eds.), The technical gesture. Methodological and anthropological reflections (pp. 113-150). Ramonville Saint-Agne, France: Erès Editions.

Bril, B. (2015). Learning to use tools: A functional approach to action. In L. Filletaz \& S. Billet (dir.), Learning through and for practice: contributions from Francophone perspectives (pp. 95-118). Springer.

Cavalli-Sforza, L. L., \& Feldman, M. W. (1981). Cultural transmission and evolution: A quantitative approach. Princeton, NJ: Princeton University Press.

Cochrane, E. E. (2008). Migration and cultural transmission: Investigating human movement as an explanation for Fijian ceramic change. In M. J. O'Brien (Ed.), Cultural transmission in archaeology: Issues and case studies (pp. 132-145). Washington, D C: Society for American Archaeology.

Cochrane, E. E., Rieth, T. M., \& Dickinson, W. R. (2013). Plainware ceramics from Sāmoa: Insights into ceramic chronology, cultural transmission, and selection among colonizing populations. Journal of Anthropological Archaeology, 32, 499-510. doi:10.1016/j.jaa.2013.08.005

Costin, C. L., \& Hagstrum, M. B. (1995). Standardization, labor investment, skill, and the organization of ceramic production in late prehispanic highland Peru. American Antiquity, 60, 619-639. doi: $10.2307 / 282046$

Creese, J. L. (2012). Social contexts of learning and individual motor performance. In W. Wendrich (Ed), Archaeology and apprenticeship (pp. 85-107). Tucson: University of Arizona Press.

Eerkens, J. W., \& Lipo, C. P. (2005). Cultural transmission, copying errors, and the generation of variation in material culture and the archaeological record. Journal of Anthropological Archaeology, 24, 316-334. doi:10.1016/j.jaa.2005.08.001

Eerkens, J. W., \& Lipo, C. P. (2007). Cultural transmission theory and the archaeological record: Providing context to understanding variation and temporal changes in material culture. Journal of Archaeological Research, 15, 239-274. doi:10.1007/s10814-007-9013-z

Endler, J. A. (1986). Natural selection in the wild. Princeton, NJ: Princeton University Press. 
Gandon, E. (2014). To what extent do traditional motor skills reveal a cultural model? Field experiments with expert French and Indian potters. Annales de la Fondation Fyssen, 29, 47-68.

Gandon, E., Bootsma, R. J., Endler, J. A., \& Grosman, L. (2013). How can ten fingers shape a pot? Evidence for equivalent function in culturally distinct motor skills. Plos One, 8, e81614. doi:10.1371/ journal.pone.0081614

Gandon, E., Casanova, R., Sainton, P., Coyle, T., Roux, V., Bril, B., \& Bootsma, R. J. (2011). A proxy of potters' throwing skill: Ceramic vessels considered in terms of mechanical stress. Journal of Archaeological Science, 38, 1080-1089. doi:10.1016/j.jas.2010.12.003

Gandon, E., Coyle, T., \& Bootsma, R. J. (2014). When handicraft experts face novelty: Effects of shape and wheel familiarity on individual and community standardization of ceramic vessels. Journal of Anthropological Science, 35, 289-296.

Gandon, E., Pous, F., Coyle, T., Buloup, F., \& Bootsma, R. J. (2011). Regulating rotation speed in wheel throwing: Effects of mass and shape. In E. P. Charles \& L. J. Smart (Eds.), Studies in perception and action IX (pp. 196-201). New York, NY: Psychology Press.

Gandon, E., Roux, V., \& Coyle, T. (2014). Copying errors of potters from three cultures: Predictable directions for a so-called random phenomenon. Journal of Anthropological Science, 33, 99-107.

Gardin, J. C. (1980). Archaeological constructs: An aspect of theoretical archaeology. Cambridge, UK: Cambridge University Press.

Gelbert, A. (2002). Technical borrowing and gestural change: Measurement of the motor constraints influencing the ceramic borrowings in the Senegal valley. In B. Bril \& V. Roux (Eds.), The technical gesture. Methodological and anthropological reflections (pp. 261-283). Ramonville Saint-Agne, France: Erès Editions.

Gibson, E. J. (1992). How to think about perceptual learning: Twenty-five years later. In H. L. Pick, P. van den Broek, \& D. C. Knill (Eds.), Cognition: Conceptual and methodological issues (pp. 215237). Washington, D C: American Psychological Association.

Gosselain, O. P. (1992). Technology and style: Potters and pottery among Bafia of Cameroon. Man, 27, 559-586. doi:10.2307/2803929

Gosselain, O. P. (2000). Materializing identities: An African perspective. Journal of Archaeological Method and Theory, 7, 187-218. doi:10.1023/A:1026558503986

Hamilton, M. J., \& Buchanan, B. (2009). The accumulation of stochastic copying errors causes drift in culturally transmitted technologies: Quantifying Clovis evolutionary dynamics. Journal of Anthropological Archaeology, 28, 55-69. doi:10.1016/j.jaa.2008.10.005

Hill, J. N. (1978). Individuals and their artifacts: An experimental study in archaeology. American Antiquity, 43, 245-257. doi:10.2307/279248

Hodder, I. (1979). Pottery distribution: Service and tribal areas. In M. Millett (Ed.), Pottery and the archaeologist (pp. 7-24). London, UK: Institute of Archaeological Occasional Publications.

Karasik, A., \& Smilansky, U. (2011). Computerized morphological classification of ceramics. Journal of Archaeological Science, 38, 2644-2657. doi:10.1016/j.jas.2011.05.023

Kempe, M., Lycett, S., \& Mesoudi, A. (2012). An experimental test of the accumulated copying error model of cultural mutation for Acheulean handaxe size. Plos One, 7, e48333. doi:10.1371/journal. pone. 0048333

Kramer, C. (1985). Ceramic ethnoarchaeology. Annual Review of Anthropology, 14, 77-102. doi:10.1146/annurev.an.14.100185.000453

Kramer, C. (1997). Pottery in Rajasthan: Ethnoarchaeology of two Indian cities. Washington, D C: Smithsonian Institution Press.

Kuhl, F. P., \& Giardina, C. R. (1982). Elliptic Fourier features of a closed contour. Computer Graphics and Image Processing, 18, 236-258. doi:10.1016/0146-664X(82)90034-X

Lewontin, R. C. (1971). The effect of genetic linkage on the mean fitness of a population. Proceedings of the National Academy of Sciences, 68, 984-986. doi:10.1073/pnas.68.5.984

McLellan, T., \& Endler, J. A. (1998). The relative success of some methods for measuring and describing the shape of complex objects. Systematic Biology, 47, 264-281. doi:10.1080/ 106351598260914

Mielke, P. W., \& Berry, K. J. (2007). Permutation methods: A distance function approach. Berlin: Springer Science and Business Media. 
Morris, C. (1993). Hands up for the individual! The role of attribution studies in Aegean prehistory. Cambridge Archaeological Journal, 3, 41-66. doi:10.1017/S0959774300000718

Newell, K. M. (1986). Constraints on the development of coordination. Motor Development in Children: Aspects of Coordination and Control, 34, 341-360.

Newell, K. M. (1991). Motor skill acquisition. Annual Review of Psychology, 42, 213-237. doi:10.1146/ annurev.ps.42.020191.001241

Oksanen, J. F., Blanchet, G., Friendly, M., Kindt, R., Legendre, P., McGlinn, D., ... Wagner, H. (2016). Vegan: Community ecology package [R package version 2.4-0]. Retrieved from https://CRAN.Rproject.org/package $=$ vegan

Orton, C. (1993). How many pots make five? An historical review of pottery quantification. Archaeometry, 35, 169-184. doi:10.1111/j.1475-4754.1993.tb01033.x

Parry, R., Dietrich, G., \& Bril, B. (2015). Tool use ability depends on understanding of functional dynamics and not specific joint contribution profiles. Frontiers in Psychology, 5, 306.

Pierret, A. (2001). Technological analysis of archaeological ceramics: methodological developments for identifying fashioning techniques. In The ceramic material of the village Arenes at Levroux (Indre, France) as a case study. Villeneuve d'Ascq, France: Presses Universitaires du Septentrion.

Read, D. W. (2009). Artifact classification: A conceptual and methodological approach. Walnut Creek, California: Left Coast Press.

Reed, E. S., \& Bril, B. (1996). The primacy of action in development: A commentary of N. Bernstein. In M. Latash (Ed.), Dexterity and its development (pp. 431-451). Hillsdale, NJ: Erlbaum.

Rein, R., Nonaka, T., \& Bril, B. (2014). Movement pattern variability in stone knapping: Implications for the development of percussive traditions. Plos One, 9, e113567. doi:10.1371/journal. pone. 0113567

Richerson, P. J., \& Boyd, R. (2005). Not by genes alone. How culture transformed human evolution. Chicago, IL: The University of Chicago Press.

Roe, P. G. (1980). Art and residence among the Shipibo Indians of Peru: A study in microacculturation. American Anthropologist, 82, 42-71. doi:10.1525/aa.1980.82.1.02a00030

Roux, V. (2003). Ceramic standardization and intensity of production: Quantifying degrees of specialization. American Antiquity, 68, 768-782. doi:10.2307/3557072

Roux, V., \& Corbetta, D. (1989). The potter's wheel: Craft specialization and technical competence. New Delhi, India: Oxford and IBH.

Roux, V., \& Karasik, A. (in press). Standardized vessels and number of potters: Looking for individual production. In J. Vukovic \& I. Miloglav (Eds.), Artisans rule: Product standardization and craft specialization in prehistoric society. Cambridge, UK: Cambridge Scholars.

Rye, O. S. (1977). Pottery manufacturing techniques: X-Ray studies. Archaeometry, 19, 205-211. doi:10.1111/j.1475-4754.1977.tb00200.x

Saraswati, B., \& Behura, N. K. (1964). Pottery techniques in peasant India (No. 13). Calcutta: Anthropological Survey of India.

Schiffer, M. B. (1976). Behavioral archaeology. Cambridge, Massachusetts: Academic Press.

Schiffer, M. B., \& Skibo, J. M. (1997). The explanation of artifact variability. American Antiquity, 62, 27-50. doi: $10.2307 / 282378$

Schillinger, K., Mesoudi, A., \& Lycett, S. (2014). Copying error and the cultural evolution of "additive" vs. "reductive" material traditions: An experimental assessment. American Antiquity, 79, 128-143. doi:10.7183/0002-7316.79.1.128

Sevrez, V., Berton, E., Rao, G., \& Bootsma, R. J. (2009). Regulation of pendulum length as a control mechanism in performing the backward giant circle in gymnastics. Human Movement Science, 28, 250-262. doi:10.1016/j.humov.2008.10.002

Sevrez, V., Rao, G., Berton, E., \& Bootsma, R. J. (2012). On the organizing role of nonmuscular forces during performance of a giant circle in gymnastics. Journal of Applied Biomechanics, 28, 57-62. doi:10.1123/jab.28.1.57

Steele, J., Glatz, C., \& Kandler, A. (2010). Ceramic diversity, random copying, and tests for selectivity in ceramic production. Journal of Archaeological Science, 37, 1348-1358. doi:10.1016/j. jas.2009.12.039 
Thomas, J. T., McCall, G., \& Lillios, K. (2009). Revisiting the individual in prehistory: Idiosyncratic engraving variation and the Neolithic slate plaques of the Iberian Peninsula. Cambridge Archaeological Journal, 19, 53-72. doi:10.1017/S0959774309000031

Whallon, R. (1972). A new approach to pottery typology. American Antiquity, 37, 13-33. doi:10.2307/ 278883

Winslow, D. (2009). The village clay: Recursive innovations and community self-fashioning among Sinhalese potters. Journal of the Royal Anthropological Institute, 15, 254-275. doi:10.1111/j.14679655.2009.01552.x 